\title{
Redes das literaturas de fronteiras como existência e pluralidade
}

\author{
Networks of Border Literatures as Existence and Plurality \\ Redes de las literaturas de fronteras como existencia y pluralidad
}

Isabel Jasinski ${ }^{*}$

\section{Resumo}

A reflexão proposta neste artigo incide sobre a questão das redes da literatura em portunhol e outras línguas, nas obras Triple frontera dreams (2012) do escritor brasileiro Douglas Diegues, Xirú (2010) do paraguaio Damián Cabrera e Viralata (2015) do uruguaio Fabián Severo. Ao pensar como alguns escritores latino-americanos compartilham a experiência do espaço de fronteira, o portunhol e as línguas de fronteira como expressão literária, a publicação de suas obras nas duas primeiras décadas do século XXI e a edição independente delas, além da sua atuação nas redes sociais, a análise pretende abordar quais mecanismos tais autores acionam para criar suas narrativas como um lugar de fala, sem configurar um discurso da imanência nem da transcendência, mas buscando modos de articulação da singularidade que se caracterizem pela noção de "comunidade de existência". A fronteira se caracteriza pela relação, seja de libertação ou de dominação, é um espaço praticado e assinalado pela pluralidade, que se manifesta como tensão social da convivência em Damián Cabrera, como melancolia de um sentido ausente, convertido em palavras e memórias inventadas em Fabián Severo, ou como gozo do presente pelo delírio em Douglas Diegues. Uma comunidade de existência que se manifesta na expressão desses escritores de fronteira, formando-se pelo contato e pela articulação de suas redes literárias.

Palavras-chave: Américas transitivas, redes literárias, literaturas de fronteira, portunhol literário.

\section{Abstract}

The reflection proposed in this article focuses on the issue of literature networks in Portunhol and other languages, in the books Triple frontera dreams (2012) by Brazilian writer Douglas Diegues, Xirú (2010) by Paraguayan Damián Cabrera and Viralata (2015) by Uruguayan Fabián Severo. By considering how some Latin American writers share the experience of the border space, the use of Portunhol and border languages as a literary expression, the publication of their works in the first two decades of the 21st century and their independent editing, in addition to their social media presence, the analysis aims at addressing what mechanisms such authors activate in order to create their narratives as a locus of ennunciation, without configuring a discourse of immanence or transcendence, but seeking ways to articulate the singularity that are characterized by the notion of "community of existence". The border is characterized by a relationship of either liberation or domination, and it is a space practiced and marked by plurality, which manifests itself as social tension of coexistence in Damián Cabrera, as melancholy of an absent meaning converted into

\section{Resumen}

La reflexión propuesta en este artículo se centra en el tema de las redes de la literatura en portuñol y otras lenguas, en las obras Triple frontera dreams (2012) del escritor brasileño Douglas Diegues, Xirú (2010) del paraguayo Damián Cabrera y Viralata (2015) del uruguayo Fabián Severo. A partir de cómo algunos escritores latinoamericanos participan de la experiencia del espacio fronterizo, el portuñol y las lenguas de frontera como expresión literaria, la publicación de sus obras en las primeras dos décadas del siglo XXI y su edición independiente, además de su actuación en las redes sociales, el análisis pretende abordar qué mecanismos utilizan estos autores para crear sus narrativas como un lugar de habla, sin configurar un discurso de inmanencia o trascendencia, sino buscando formas de articular la singularidad que se caracteriza por la noción de "comunidad de existencia". La frontera se caracteriza por la relación, ya sea de liberación o dominación, es un espacio practicado y marcado por la pluralidad, que se manifiesta como tensión social de convivencia en Damián Cabrera, como melancolía de un sentido ausente, convertida en palabras y

\footnotetext{
Universidade Federal do Paraná (UFPR), Curitiba, Paraná, Brasil. Eorcid.org/0000-0002-5649-1617. E-mail: belisabel.kisa@gmail.com
} 
words and invented memories in Fabián Severo, or as enjoyment of the present via delirium in Douglas Diegues. It is a community of existence that manifests itself in the expression of these frontier writers, formed by the contact and articulation of their literary networks.

Keywords: transitive americas, literary networks, frontier literature, literary portunhol. recuerdos inventados en Fabián Severo, o como disfrute del presente por el delirio en Douglas Diegues. Una comunidad de existencia que se manifiesta en la expresión de estos escritores fronterizos, formada por el contacto y la articulación de sus redes literarias.

Palabras-clave: américas transitivas, redes literárias, literaturas de frontera, portuñol literário.

\section{Babel [...] parece ser a imagem que rege o presente espetáculo de nossas sociedades. Babel como imagem da confusão e da entropia, ou Babel como divisa libertadora do multiculturalismo? Babel como estratégia de uma economia global neoliberal, ou Babel como resultado da resistência cultural dos indivíduos? \\ Hugo Achúgar \\ O ter-lugar, o comunicar das singularidades no atributo da extensão, não as une na essência, mas as dispersa na existência.}

Giorgio Agamben

\section{Práticas literárias contemporâneas}

As discussões sobre identidade e alteridade marcaram o pensamento do século XX e ganharam intensidade nas duas décadas finais, como resposta aos processos sociais e culturais antenados ao desenvolvimento tecnológico dos meios de comunicação de massa e aos processos econômicos transnacionais, que apontavam para uma reconfiguração do mundo. Essas questões foram lançadas como dados no tabuleiro da virada do século XXI e se desdobraram em modos expressivos da literatura pautada especialmente pela articulação entre arte e vida, ficção e realidade, literatura e outras linguagens ou diferentes suportes, como a poesia visual ou a escrita performática. Em outras palavras, apontaram para a permeabilidade das fronteiras e o atravessamento entre sujeito, real e linguagem. Como decorrência desse processo de reconfiguração do sentido do que seja "literário" hoje, muitas escrituras deixaram de corresponder ao cânone e buscaram meios de promover sua produção artística. A facilidade do acesso aos meios digitais de comunicação e os processos de globalização redefiniram os modos de circulação dessas práticas. Em diálogo com os meios, técnicas e linguagens, uma parte da produção literária atual buscou projeção em editoras independentes, como as cartoneras em vários países latino-americanos, mas também em redes sociais, como blogs, Youtube ou Facebook.

Na esteira das relações entre o ser, o saber e o fazer, entre potência e ato, relacionado aos novos procedimentos da prática artística literária contemporânea, configura-se, todavia, uma sensibilidade daquilo que Jacques Rancière chamou "regime estético das artes", como sendo "aquele que propriamente identifica a arte no singular e desobriga essa arte de toda e qualquer regra específica, de toda hierarquia de temas, gêneros e artes" (2005, p. 33-34). Esse é o enquadramento da autonomia moderna das artes, que se pauta pela busca do novo, a ruptura com a sensibilidade instituída e "a reinterpretação daquilo que a arte faz ou daquilo que a faz ser arte" (Rancière, 2005, p. 36). Segundo o filósofo, o Pós-modernismo, nesse processo, promoveu a contestação da autonomia determinada como princípio "modernitário" (Rancière, 2005, p. 42). As escrituras contemporâneas, que atravessam as fronteiras do literário, são sintomas dessa contestação. Conforme defendeu Josefina Ludmer (2010, p. 151), elas configuram as literaturas pós-autônomas, reformulando as categorias de realidade e ficção, a partir do postulado de que a realidade é ficção e a ficção é realidade, para fabricar o presente. Sem querer estender essa discussão, vale a pena destacar aspectos importantes observados pela crítica, que permitem uma reflexão sobre a literatura produzida posteriormente aos anos 2000, como a relação entre arte e 
vida, e a articulação entre literatura e outras linguagens, meios e suportes apontados inicialmente, além dos atravessamentos entre ficção e realidade.

Isso redefine os modos de circulação dos produtos artísticos e integra os espaços descentralizados em uma rede de sentidos que recoloca em pauta as relações entre território, comunidade e linguagem no começo do século XXI, como marcas do que se pode chamar genericamente de literaturas de fronteira. Contudo, nas escritas em portunhol e demais línguas da fronteira, essa dinâmica se potencializa com a des(re)territorialização, conforme a compreensão de Deleuze e Guattari (1995), como um processo não apropriável, múltiplo e agramatical. A reflexão proposta neste artigo incide sobre a questão da comunidade e das redes literárias a partir de Triple frontera dreams, do escritor brasileiro Douglas Diegues (2012), Xirú, do paraguaio Damián Cabrera (2010), e Viralata, do uruguaio Fabián Severo (2015). Ao pensar como alguns escritores latino-americanos compartilham aspectos relacionados à experiência do espaço de fronteira, ao portunhol e às outras línguas fronteiriças em tensão como expressão literária, à publicação de suas obras nas duas primeiras décadas do século XXI e a edição independente delas, além da sua atuação nas redes sociais, a análise pretende abordar quais mecanismos tais autores acionam para criar suas narrativas como um lugar de fala, o "ter-lugar" de Agamben (1990/2013, p. 27), sem configurar um discurso da imanência nem da transcendência, mas buscando modos de articulação da singularidade que se caracterizem pela noção de "comunidade de existência" ${ }^{1}$ criando redes literárias como aquilo que excede as concepções de indivíduo, obra e literatura nacional. Nessa linha, o fluxo das redes literárias se estabelece nas conexões "outro(s)/linguagem/eu/linguagem/outro(s)" para caracterizar uma experiência multidirecional de sentidos, em que o "eu" narrativo é passagem ativa na significação, não origem unívoca. Faz parte de um processo não linear de experimentação da linguagem como relação, por meio do corpo singular, um dentro fora, enquanto escrita nômade. Isso produz um sentido de impermanência, precariedade, desvio e vazio que a literatura escrita em portunhol - também em línguas que convivem na fronteira, marcando diferenças sociais e culturais, como em Xirú - acentua nessas obras, para defender, contudo, um lugar de fala que é, ao mesmo tempo, afetivo e político, nunca absoluto.

\section{A expressão nas fronteiras da singularidade}

É preciso não parar de escrever, não deixar de expor o traçado singular de nosso ser em comum.

Jean-Luc Nancy

As questões que Hugo Achúgar lança em seu artigo "Repensando a heterogeneidade latinoamericana" de 1996, publicado na Revista Iberoamericana da Universidade de Pitsburg, ainda ressoam nesta segunda década de começo de século. É sintomático o fato de que o texto seja reeditado dez anos depois em Planetas sem boca (Achúgar, 2006) - não só por reunir a reflexão do autor nesse período. Partindo do reconhecimento de um "nós" latino-americano heterogêneo, deslocado e mutante, nessa obra (Achúgar, 2006, p. 23), o pensador uruguaio relança suas perguntas sobre a crescente conexão dos indivíduos na América Latina e no mundo, se ela atua como integradora de um imaginário único ou se "as peculiaridades locais operam como um desconstrutor desse imaginário global e transnacional" (Achúgar, 2006, p. 84).

\footnotetext{
${ }^{1}$ Noção desenvolvida a partir de textos importantes que fundamentaram a discussão dos anos 1980 em diante, postulada inicialmente por Jean Luc-Nancy em um artigo publicado na revista Alea, em 1983, relendo as proposições de Geoges Bataille e Marcel Mauss, ao qual respondeu Maurice Blanchot com A comunidade inconfessável, no mesmo ano. Em seguida, Nancy desenvolveu a questão no livro A comunidade inoperada (2016 [1986]) e em outras obras como A comunidade afrontada, em 2001, e A comunidade desautorizada, em 2014. Em 1990, Giorgio Agamben também refletiu sobre o tema em A comunidade que vem, entre outros filósofos, como Roberto Espósito, em várias publicações desde Communitas. Origine e destino della comunità em 1998. Nessa linha, a "comunidade de existência" pode ser entendida como um espaço praticado pelo ser-em-comum, que rejeita uma identidade única e se abre para a heterogeneidade, por isso Agamben considera que o "comunicar das singularidades" "as dispersa da existência", não as "une na essência".
} 
[...] poder-se-ia perguntar se a transformação tecnológica-política, ocorrida nos últimos tempos - aludida em parte nessa realidade, ou o efeito universalizador que se chama globalização - mudou realmente as identidades locais e nacionais? Ou, inclusive, poderia se perguntar se a tão célebre globalização esteve ou está construindo uma única e global identidade? Ou se, pelo contrário, as identidades múltiplas, flutuantes ou migratórias, de que se fala como um dos fenômenos contemporâneos, nega o pressuposto de uma identidade única e global (Achúgar, 2006, p. 83).

Como forma de resistência à homogeneidade globalizada, Achúgar retoma a discussão sobre a heterogeneidade proposta por Antonio Cornejo Polar em Escribir en el aire, publicado em 1994, ainda que considere que não se trata de um fenômeno exclusivo da cultura latino-americana (Achúgar, 2006, p. 89). Contrário à coexistência universalista de Arjun Appadurai, Achúgar defende a importância de uma "memória-paisagem" ou "monumento-paisagem" que configuram a identidade (Achúgar, 2006, p. 96), alimentando a diferença pressuposta na heterogeneidade para acentuar a tensão cultural e a consciência da desigualdade em nossas sociedades. Para ele, é preciso repensar as categorias de centro e periferia, mas também a de heterogeneidade latino-americana, tanto dentro como fora das dicotomias global/local e mundo/aldeia (Achúgar, 2006, p. 97). "Em que medida noções como comunidade, nação, região e continente modificam a própria noção de heterogeneidade?” - questiona Achúgar -. Haveria outras categorias mais adequadas como hibridação, transculturação, mestiçagem? Principalmente, sua reflexão sugere repensar noções como "comunidade latino-americana", seus espaços e seus tempos, "os temas das migrações, as viagens e todos os deslocamentos nos territórios e não territórios do presente fim de século" (Achúgar, 2006, p. 99). Essas questões reverberam sobre as primeiras décadas do século XXI, em que a experiência da comunidade, como compartilhamento e rede, gera mudanças de perspectiva sobre a expressão, os processos e os produtos culturais latino-americanos.

A partir de outro ponto de vista, ao fazer uma análise crítica dos mesmos conceitos discutidos por Achúgar em 1996, Abril Trigo, em "De la transculturación (a/en) lo transnacional" (1997, p. 154), considera que a complexificação da heterogeneidade social sob o impacto do transnacionalismo, em que coexistem múltiplas e desiguais lógicas de desenvolvimento, resulta em noções como "hibridismo cultural" de Néstor García Canclini, que segue a genealogia da modernidade latino-americana traçada por Jesús Martín-Barbero. Parece superar o consensual da síntese dialética, segundo Trigo, suposto na ideia de mestiçagem e subjacente aos conceitos de "transculturação" de Ángel Rama e de "heterogeneidade cultural" de Antonio CornejoPolar, mas acaba se refugiando na generalidade, a ponto de "não qualificar nada, ao abarcar tudo", incidindo em uma inconsistência teórica (Trigo, 1997, p. 157). Após passar em revista os conceitos correntes que buscavam dar conta da complexidade cultural latino-americana, Abril Trigo opta por não descartar o "instrumental hermenêutico" proporcionado pela "transculturação", porém propõe atualizá-los como "transculturas híbridas" ou "heterogeneidade transcultural" ou "transculturação (no) transnacional" (Trigo, 1997, p. 163), para pensar sobre os modos de produção e consumo cultural daquele período. ${ }^{2}$

Todas essas reflexões no campo da filosofia e dos estudos culturais são respostas a processos histórico-culturais emergentes no final do século XX e em princípios do século XXI, relacionados à globalização e à internacionalização das relações comerciais e comunicativas. Os acordos comerciais por regiões, que marcaram os anos de 1990 (como o Tratado de Maastricht da Comunidade Europeia, em 1993, o Mercosul e o Nafta, em 1994) promoveram a integração regional, ao mesmo tempo que alinharam forças econômicas em relações transnacionais, produzindo, entre outras coisas, maior circulação de bens culturais, facilitando a relação entre nações, o atravessamento de fronteiras e o plurilinguismo. Josefina Ludmer aponta que a economia reorganizou o território em novas formas de territorialização do poder e das artes,

\footnotetext{
${ }^{2}$ Em sua discussão sobre Americanidade e transferências culturais, Zilá Bernd (2003) também avalia os desdobramentos dos conceitos de transculturação e heterogeneidade cultural, incluindo noções como crioulidade, a partir de Éloge de la creolité, publicada em 1989 pelos escritores caribenhos Jean Bernabé, Patrick Chamoiseau e Raphaël Confiant, além de características do pensamento da margem (Walter Mignolo) e da lógica da diversidade (Edóuard Glissant) (Bernd, 2003, p. 19).
} 
produzindo espacialidades que pertencem tanto ao global como ao nacional, regional e local (Ludmer, 2010, p. 124). Em consequência, a literatura deixou de ser manifestação do nacional, para se tornar lugar e cenário de outras subjetividades e políticas (Ludmer, 2010, p. 135). Contudo, mesmo reconfigurando um imaginário espacial que buscava expressar aquele processo de transição, Maria Eugênia Bancescu $(2012$, p. 3) lembra que, para Hugo Achúgar, a noção de território continuava valendo no marco do Mercado Comum do Sul. Isso leva a pensar que, se esse parâmetro ainda vige nas relações comerciais em razão de sua propriedade e origem, os bens imateriais se manifestam em parte como fluxo e desterritorialização, beneficiados pela abertura de fronteiras.

No caso específico dos países do Cone Sul, as fronteiras aparecem como lugares de trânsito e delírio nos textos de Douglas Diegues, cartografia social no texto de Damián Cabrera e território afetivo da memória no texto de Fabián Severo. Para Cabrera, a fronteira se caracteriza por suas cartografias superpostas, pontuando modos de ver que atribuem valor ao lugar e existem em função do lugar, como observa em "Notas para representarse, decires en frontera":

Nesse espaço atravessado por territorialidades em conflito, que lutam para se consolidar e, às vezes, se impor a outras, há indícios de um campo aberto a múltiplas semanticidades; a proximidade e as relações de poder dão origem a atravessamentos possíveis: o ingresso em outros universos simbólicos; mas também promovem outros tipos de cruzamentos: há interferências linguísticas, há aculturação e também hibridizações (Cabrera, 2014, p. 169, tradução nossa).

Apesar de suas diferenças, esses escritores nasceram ou cresceram nas fronteiras entre Brasil e Paraguai e Brasil e Uruguai, e suas escritas possuem relação com a experiência vivida na infância e com o imaginário da fronteira como conteúdo simbólico. Para muitos críticos, as fronteiras são múltiplas e precisam ser pensadas no plural, porque congregam muito mais do que a simples demarcação territorial, política e econômica de uma nação. Configuram a perspectiva da margem, como resposta epistêmica anti-imperial, para Josué Ferreira Oliveira Júnior (2018, p. 16) na esteira de Walter Mignolo. "São entre-lugares compartilhados, locais de alteridades e constante interação entre as identidades, sobretudo lugar que aproxima os diferentes entre si", na análise de Angela Cristina Dias do Rego Catonio (2018, p. 22), que conformam uma zona social, na concepção da geografia humanista. Segundo a pesquisadora, as práticas culturais fronteiriças engendram intencionalidades que se apropriam do espaço comum para manifestar a afetividade e o pertencimento (Catonio, 2018, p. 76). Existem muitos estudos que abordaram esse tema nas obras dos escritores mencionados, pois a fronteira é uma questão inalienável quando se pensa sobre as literaturas escritas em portunhol e nas línguas de fronteira. Sem ignorá-la, esta reflexão se propõe a discutir se o espaço praticado da fronteira e a expressão em portunhol, guaraní, espanhol e português nessas obras, vinculados a modos de relação, articulação e circulação, configuram uma comunidade de existência pautada pela singularidade plural.

No final do século XX, a discussão sobre comunidade acontece paradoxalmente no extremo da dissolução da comunidade, lembra Márcia Sá Cavalcanti Schuback no prefácio à edição brasileira de A comunidade inoperada (Nancy, 2016, p. 15), mediante o fortalecimento do individualismo da sociedade global de consumo ou do Estado totalitário, amparados pela lógica imanentista da identidade e da essência. O pensamento da comunidade critica a imanência totalizante - que constrói novas identidades ou reconstrói identidades retrospectivas, porém continua excluindo o diverso - ao propor a reflexão sobre o ser-em-comum, de modo geral ausente da metafísica do sujeito (Nancy, 2016, p. 30). No entanto, não pretende fundar outra concepção absoluta de um "nós" abstrato, mas explorar o pensamento do ser-singular-plural, que se expõe na relação e só existe a partir dela, concebendo a existência como saída de si (do latim, ex-sistere, sair de, mostrar-se). A comunidade de existência inscreve, para o filósofo, a impossibilidade da comunidade como projeto fusional ou produtor de sentidos universais. $\mathrm{O}$ "estar-fora-de-si" da existência constitui o ser-comunicando e não o ser-representando, ele viabiliza "lugares da comunicação" nas fronteiras da singularidade, definidos e expostos pelo seu deslocamento, em que se dá a comunidade e a partilha, na/pela escritura, pela literatura (Nancy, 2016, p. 56-57). Nancy enfatiza que a singularidade não faz obra, por isso a comunidade 
que se efetiva na relação é inoperada e finita, surgindo do entrelaçamento e da partilha de singularidades enquanto rede.

Diferentemente de outros pesquisadores, como Catonio (2018, p. 229), esta reflexão parte do pressuposto que os autores e as obras elencados para este estudo possuem um caráter exemplar, no sentido que Giorgio Agamben $(2013$, p. 18) considerou em A comunidade que vem: nem universalista nem particular, porque não pretendem postular uma identidade absoluta nem desvendar a essência do ser da fronteira. Mesmo que suas experiências sejam primariamente pessoais, como a infância nesse espaço fronteiriço e o caráter social ou familiar do portunhol e das outras línguas, elas têm lugar na literatura como singularidades expostas e partilhadas que se deslocam pela linguagem. Por mais que publiquem obras, elas são inoperadas, porque estão em processo, modificadas a cada nova edição - como é o caso de Triple frontera dreams, nas edições de Eloísa Cartonera (Diegues, 2012) e de Interzona (Diegues, 2017) -, não revelam nenhuma verdade inquestionável, mas, antes, comunicam a oscilação da fala e a precariedade das relações. Por isso mesmo, os autores defendem que o portunhol deve permanecer agramatical, permitindo que cada pessoa crie seu próprio portunhol no ato de comunicação. Os exemplos da literatura em portunhol se caracterizam pela multiplicidade e pela des(re)territorialização da expressão, noções simpatizantes do ser-singular-plural. Desse modo, o portunhol literário, assim como as edições independentes dessas obras e a performance dos autores nas redes, pode configurar um uso ou um ethos, como entendeu Agamben (2013, p. 28), que marca a passagem do comum ao próprio e do próprio ao comum. Esse deslocamento é político na medida em que é a experiência consciente de uma partilha do ser-em-comum, que só existe na relação.

Vários estudos dedicados a pensar sobre as literaturas escritas em portunhol consideram-nas representativas da fala da fronteira, por esse motivo qualificam o portunhol como uma língua de contato ou pidgin (Alós, 2012; Bancescu, 2013; Catonio, 2018). Catonio (2018, p. 77) avalia que se trata de uma "língua franca", comum e capaz de conformar um substrato simbólico do qual o portunhol literário seria expressão, entendendo que existe um modelo anterior da linguagem a ser transposto por "processos identitários próprios". Por outro lado, a relação entre as línguas da fronteira, na visão de Damián Cabrera (2014, p. 172), operaria como uma montagem de imagens e ficções, capaz de dizer uma experiência e habilitar novas formas de subjetividade, redistribuindo posições discursivas e políticas, em sentido contrário ao agenciamento do poder econômico que coloniza os sentidos. Isso acontece na região do Alto Paraná, segundo ele, onde o português é língua colonizadora que desloca os sentidos em relação ao castellano/guarani e às demais línguas das coletividades imigrantes da região. Essas misturas constroem relações subordinantes, "excluindo outros modos de estar no lugar" (Cabrera, 2014, p. 177), mas também configuram oportunidades criativas que poderiam transgredir hierarquias no livro e no território. No caso das fronteiras entre o Brasil e o Paraguai, para Damián Cabrera, o fator econômico é determinante das relações entre indivíduos que compartilham o espaço do Alto Paraná e se comunicam em portunhol. Isso é inerente também ao uso das línguas que fazem os paraguaios e brasiguaios ${ }^{3}$ de diferentes origens sociais e culturais, como se percebe pela dinâmica narrativa de Xirú, que alterna fragmentos de situações expressas em castelhano, guarani, português e algumas inserções do portunhol, como meio de marcar as diferenças sociais, mas também o tempo, pois as lembranças de infância do narrador são descritas em guarani e as elucubrações mentais do adulto se desenrolam em espanhol.

Eso pasaba cuando me debatía en mi sillón de aspecto desgraciado fumando los pitillos del cenicero, aterrorizado por las responsabilidades; aquéllas que a veces nos proporcionan cierta falsificada seguridad, cierta ansiedad dignificada que pasa por esperanza para arrastrar con una pesadumbre más tolerable ese sol gris y maloliente; recordaba algún episodio de la niñez, de la adolescencia, o imaginaba el futuro, y nacía el cuento (Cabrera, 2010, p. 68).

\footnotetext{
3 “[...] pequenos proprietários rurais da região da Bacia do Rio Paraná que, obrigados a abandonar a região por ocasião da construção da Barragem de Itaipu, utilizaram as indenizações recebidas pela desapropriação de suas terras para a compra de outras no Paraguai, em função dos baixos preços, onde reconstruíram suas vidas” (Alós, 2012, p. 294).
} 
Diante da complexidade dos atravessamentos entre línguas na fronteira do Brasil com o Paraguai, Catonio destaca que chamar "portunhol" a essa língua é insuficiente, porque não inclui o guarani, por isso Douglas Diegues a denomina "portunhol selvagem" (Catonio, 2018, p. 57). Do ponto de vista deste artigo, essa não seria a única razão da denominação de Diegues para sua língua literária, visto que ele insere livremente nos seus textos palavras de outras línguas, como o italiano, o árabe, o inglês e outras línguas indígenas minoritárias no Paraguai. Sua selvageria decorre do desregramento como dinâmica da expressão, marcada pelo êxtase e pelo delírio nas relações com os outros.

No caso da fronteira com o Uruguai, pode-se dizer que o ímpeto colonizador do Brasil é muito anterior ao dos brasiguaios, confundindo-se com a história da delimitação das fronteiras do Império do Brasil, antes do seu estabelecimento em 1828. Por muito tempo a região Norte do Uruguai teve o português como língua materna; somente no começo do século XX o Uruguai estabeleceu a segregação dessa língua. Catonio destaca que "de acordo com Luis Ernesto Behares (1984), nos departamentos uruguaios de Artigas, Rivera e Cerro Largo, todos localizados ao Norte do Uruguai, 'se habla portugués desde el siglo XVIII y no hace aun cien años que se habla español en situación de segunda lengua'"' (Behares apud Catonio, 2018, p. 50). A presença do português no Uruguai é tão marcante que foi reconhecido desde 2009 como Português do Uruguai, uma língua materna que surgiu do multilinguismo da região, portanto, uma língua crioula, falada por cerca de $15 \%$ da população uruguaia na chamada "fronteira da Paz", unindo as cidades de Artigas e Rivera (Uruguai) a Quaraí e Santana do Livramento (Brasil). Isso ajuda a entender a relação afetiva que se manifesta no uso do portunhol por Fabián Severo, que ele constantemente enfatiza nos seus textos e entrevistas: "as palavras do afeto, da ternura, das emoções, da paixão são do idioma materno. Não posso recriar nem expressar meu passado sem elas" (Severo, 2012, s.p., tradução nossa). Em Viralata, a língua é o vínculo entre o protagonista e a figura materna ou os moradores da fronteira na cidade de Artigas. $\mathrm{O}$ ambiente escolar, entretanto, é o disparador da consciência do menino acerca de sua inadequação pelo uso do portunhol e pela deficiência da linhagem familiar, já que não conhecia seu pai. A tensão entre a exigência legisladora e o deslocamento da consciência de si produz a narrativa como exposição do ser que assume sua condição de "vira-lata", sem origem definida.

A partir desses exemplos, é possível afirmar que não há homogeneidade nas expressões literárias em portunhol, e outras línguas fronteiriças, que se inscrevem no limiar entre a fala e a escrita, entre a singularidade das narrativas e a pluralidade de cada experiência de fronteira. ${ }^{4}$ Desse modo, elas se constituem como lugares deslocados de fala, lugares de compartilhamento entre o interior da experiência vivida e o exterior da relação. Essas literaturas em portunhol podem ser vistas como "divisa libertadora do multiculturalismo" e "resistência cultural dos indivíduos", que, como apontou Achúgar (2016, p. 85), contribuem para a Babel da "sociedade telemática", sem deixar contudo de alimentar a entropia do sistema, porque essa dinâmica narrativa não pretende instaurar nem imanência, nem transcendência, do ponto de vista desta análise. Assim, os autores se colocam como ativistas de uma nova geografia, como destaca María Eugenia Bancescu (2013, p. 9), ao escreverem em uma língua deslocada, ao desafiarem a indústria tradicional do livro por conta própria ou de maneira cooperativa, como é o caso das editoras cartoneras. Da mesma maneira, seu ativismo estético se observa pela atuação nas redes sociais, principalmente blogs, Facebook e canais de Youtube..$^{5}$ Diegues, Cabrera e Severo possuem blogs, nos quais publicam seus textos, imagens e críticas das suas obras. Para Cabrera e Severo, o Facebook tem servido como plataforma para a divulgação das suas atividades

\footnotetext{
4 “[...] el portunhol selvagem es uma literatura non-oficial que pode ser situada, temporariamente, nesse lugar ninguno, entre ambos lados de las fronteras" (Gasparini et al., 2012, p. 161, tradução nossa).

5 "Nessa perspectiva, é possível pensar a poética de Diegues como um deslocamento das cartografias a partir das quais o centro e a periferia foram definidos desde a modernidade. Seus escritos podem ser lidos como uma redefinição perturbadora das categorias de nação e literaturas nacionais, com base na corrosão das noções de língua, identidade e território. // Por outro lado, a divulgação da sua obra através de blogs e editoras cartoneras constitui uma margem a partir da qual se questiona "a função central" da consagração legitimadora do mercado e das instituições, contexto em que o "portunhol selvagem" se impõe como fenômeno literário de resistência cultural diante da absorção do mercado e ao mesmo tempo como estratégia político-poético-linguística para se situar no centro do debate intelectual" (Bancescu, 2013, p. 3-4, tradução nossa).
} 
literárias. Douglas Diegues se caracteriza pela sua atuação em público falando em portunhol, registrado em entrevistas, feiras e lançamentos, também no Youtube, ${ }^{6}$ o que faz parte da sua performance, tornando-o personagem de sua obra em deslocamento.

\title{
A pluralidade nas redes literárias das fronteiras
}

\begin{abstract}
En esa instancia poética el portuñol no valdrá apenas como error o interferencia, sino que su uso comportará un sentido pleno, positivo. Ya que si podemos acusar de error al hablante, no será tan desacreditador acusar de errar al poeta. El lugar desde donde habla el poeta se muestra excesivamente movedizo e inestable.
\end{abstract}

Néstor Perlongher

[...] a única razão por que estamos aqui é porque viemos para encontrar com outras pessoas, porque não viemos a encher-nos de objetos, viemos para encher-nos de amigos. Esse dia, o Portunhol será a língua que possibilitará o encontro dos povos. Quando descobrirmos que a única pátria possivel é a do encontro, do diálogo, esse dia o Portunhol será a nossa língua.

Fabián Severo

A criação literária de línguas a partir de práticas da oralidade não é exclusiva da contemporaneidade, mas ganhou força especialmente desde o começo do século XX, em que se destacam muitos exemplos latino-americanos de criação literária de línguas, como nas obras de Sousândrade, Oliverio Girondo, João Guimarães Rosa, José María Arguedas, entre outros. No caso do portunhol, Contos gauchescos (1912) e Lendas do sul (1913), de Simões Lopes Neto, La divina increnca (1915) de Juó Babanére,7 e o conto homônimo de Los desterrados (1926), de Horacio Quiroga, podem ser considerados antecessores dessa expressão literária, comenta Diego Portillo (2018, p. 31, 32). Além deles, cabe destacar o projeto linguístico do artista argentino Xul Solar que, inscrito no movimento martinfierrista, juntamente com Jorge Luis Borges, e outros escritores, propôs, nos anos de 1920, a criação do neocriollo, uma mistura de espanhol e português, para ser usado como língua franca em toda a América Latina. Contudo, o neocriollo deveria estar subordinado à normatização para garantir sua comunicabilidade, conforme entendia o artista, contrariamente ao movimento contemporâneo do portunhol, defensor da agramaticalidade desta expressão literária. Por outro lado, em seu clássico texto "El portunhol em la poesia", apresentado em 1984 no Encontro de Professores de Espanhol do Estado de São Paulo, realizado na Universidade de São Paulo, Néstor Perlongher (2000) aponta as obras Serafim Ponte Grande (1933), de Oswald de Andrade, Galáxias (escrito entre os anos de 1963 e 1975, publicado na íntegra em 1984) de Haroldo de Campos e alguns trechos de Capítulo decapitado (1981) do mexicano Héctor Olea, como exemplos do portunhol literário. Além destas obras, Catonio (2018, p. 86-87) observa que existem várias manifestações do portunhol literário no Uruguai, como Brindis agreste (1947), do poeta e escultor Agostín Ramón Bisio, La sombra de los plátanos (1950), de Olyntho Maria Simões, e Fronteras de Joaquim Coluna (1975), de Saul Ibargoyen Islas. Damián Cabrera assinala também El último vuelo del pájaro campana (1995), do escritor paraguaio Andrés Colman Gutiérrez (2014, p. 175-176, tradução nossa), e considera que, na primeira década do século XXI, "aqueles que se alinhavam ao 'portunhol selvagem' viam as interferências linguísticas como uma instância criativa e configuravam uma zona de interferências que não respondia aos mecanismos ou economias da linguagem coloquial". Importante registrar também a presença do portunhol no conto "A verdadeira estória de Sally Can Dance (and The Kids)", de Caio Fernando Abreu, que compõe a coletânea Pedras de Calcutá de 1977 (Alós, 2012, p. 292) e a publicação de El goto: cuasi, cuasi, señor de madureira (1998) do brasileiro residente no

\footnotetext{
6 Como o vídeo "MultiplicidadeS - Identidades de MS", lançado em 29 de maio de 2020. Disponível em: https://www.youtube.com/watch?v=nLXztFmrUi8. Acesso em: 23 jul. 2020.

${ }^{7}$ Apesar de registrar comicamente as interferências do italiano no português no começo do século passado, Douglas Diegues o coloca como antecedente do portunhol selvagem.
} 
Paraguai, José Eduardo Alcázar. Esta breve cronologia, sem o intuito de esgotar a questão, 8 não poderia deixar de incluir Mar paraguaio (1992), de Wilson Bueno, uma referência importante para escritores como Douglas Diegues, como muitos já destacaram.

Apesar de haver uma produção extensa em portunhol literário, tanto no Brasil como em outros países latino-americanos, pontualmente no Paraguai e no Uruguai, ela não foi contínua na obra da maioria desses escritores, muitas vezes aparecendo em fragmentos esparsos. Pode-se dizer que somente no século XXI apresentou-se uma intenção estética do portunhol literário como prática política, enquanto partilha do sensível, como entendeu Rancière (2005, p. 17), explicitando modos de reformulação da sensibilidade em contrapartida ao sistema das formas estabelecidas a priori. Nesse horizonte, a edição independente das obras e as performances dos escritores nas suas redes literárias, eventos, feiras e redes sociais são evidência dessa intencionalidade. Merece destaque o $1^{\mathrm{o}}$ Encontro Interfronteiras do Portunhol Selvaje de Poesia intitulado Asunción, kapital mundial de la fikción, em 2007, que desatou no Paraguai um debate efêmero, mas intenso, lembra Damián Cabrera (2014, p. 174). Os que participaram do encontro apresentaram uma "Karta-Manifesto-delAmor-Amor-en-Portunhol-Selvagem", com assinaturas de intelectuais, poetas e artistas do Brasil, do Paraguai, da Argentina, de Portugal e dos Estados Unidos, caracterizando-se pelo forte teor político mediante uma intervenção contra a exploração dos países pela "Gluebolândia" e o consumo desenfreado, a favor do investimento em educação e cultura.

Enquanto el lucro CREA apenas pelos em las bolas mofando em bancos de todo el mundo, perde-se el kalor del MOMENTO MÁXIKO de investir em educación, TRANSEDUCACIÓN, PÓST-EDUCACIÓN, contra la barbárie de la COBIZA y de la RABIA Y DE LA IGNORÂNCIA associada al lucro y la possesión de bienes y objetos materiales (Diegues et al., 2008, s.p., tradução nossa).

Nesse mesmo ano, com o apoio de Washington Cucurto e Javier Barilaro, alguns artistas envolvidos no movimento criaram a cartonera Yiyi Jambo: Douglas Diegues, o Domador de Yakarés, codinome para o poeta Amarildo da Silva, e a jornalista Carla Fabri. Mais recentemente, em 2015, houve um movimento entre intelectuais uruguaios e brasileiros a favor de converter o portunhol em Patrimônio Cultural e Imaterial da Unesco (Catonio, 2018, p. 58), marcado por um ciclo de conferências chamado "Jodido bushinshe - del hablar al ser", que pretendia incentivar o debate intelectual sobre a questão. Cabe destacar ainda que, durante as duas primeiras décadas do século XXI, no Brasil, intensificou-se o interesse pela pesquisa acadêmica sobre as literaturas escritas em portunhol, como se comprova pela defesa de teses e dissertações, pela organização de eventos e pelos artigos e entrevistas publicados.

"Portunhol selvagem", portunhol riverense, portuguarañol ou espangués, a multiplicidade embutida na prática do portunhol como língua literária se mostra pela variedade de modos expressivos dos escritores contemporâneos, valorizando a liberdade criativa em que cada pessoa cria seu portunhol. Nas redes literárias de Douglas Diegues, como exemplos dessa singularidadeplural, estão conectados o transportuñol borracho de Joca Rainers Terrón, o portunhol kabrobol de Xico Sá, mas também o poro'unhol de Cristino Bogado, "versão paraguaia do jopará literário", entre outros, que passaram a circular eminentemente em editoras cartoneras.

Cada persona nasce ya com suo portunhol selvagem próprio, personal, intransferíbelle. Sousândrade hay inventando el procedimento de suo próprio portunhol selvagem nel Inferno de Walt Street, em que se mesclam el tupi ameríndio, espanhol, portugês y mais 4 ou 5 lenguas. Wilson Bueno hay inbentado el suyo com suo papyro mais rarófilo, el Mar Paraguayo. Xico Sá hay inventado el portunholito kabrobol xicosáensis com la nobela Caballeros solitários rumbo al sol poente. Ronaldo Bressane inventou el portunhol salbahem ronaldobressaniensis com Cada vez que ella dice X. Joca Reiners Terrón lo inbentou a suo modo terrónnnnnniensis, mesclando non guaraní, pero ishir-chamacoco a um portunhol selvagem muy dele em Monarks atravessam el Apa. Bruno Torturra lo inventa como um

\footnotetext{
${ }^{8}$ Douglas Diegues (apud Portillo, 2018, p. 44) registra que Juana de Ibarbourou também escreveu em portunhol, Damián Cabrera (2012, p. 175) menciona Paulo Leminski.
} 
Waldick Soriano chaqueño esperando sua Stefanía entre baratones nocturnos paraguaianos (Diegues, 2009, s.p., tradução nossa).

Trata-se de um fenômeno linguístico e cultural que migrou para as poéticas de escritores argentinos, paraguaios e brasileiros (Alós, 2012, p. 290), tais como Washington Cucurto, Wilson Bueno, Douglas Diegues, Joca Rainers Terrón, El Domador de Yakarés e Andrés Colman Gutiérrez. Josué Ferreira Oliveira Júnior destaca como o movimento ganhou força nos últimos anos, referindo-se às publicações não literárias, que coincidem em alguns aspectos para ressaltar o "caráter corrosivo que lhe é intrínseco [ao fazer artístico-literário do 'portunhol selvagem'], sobretudo, no que diz respeito à maneira desconcertante com que lida com antigas e sacralizadas convenções em torno das línguas, da literatura, do literário e da própria noção de fronteira" (Oliveira Júnior, 2018, p. 7). Da perspectiva adotada nesta análise, todas essas manifestações, incluindo textos literários e não literários, podem ser vistas como as "fronteiras da singularidade" (Nancy, 2016, p. 59), que mostram o nascimento infinito de sua finitude como rede, entrelaçamento e partilha de singularidades. Reconhecem limiares de contato e passagem, pontos de conexão do portunhol literário, porém formam atravessamentos de sentidos múltiplos, que não se estabilizam em identidades e conceitos, mesmo que muitas leituras críticas busquem identificar a criação literária em portunhol com expressão de uma língua preexistente e de uma identidade fronteiriça essencial. Fazem parte dessa rede escritores e intelectuais brasileiros: Ronaldo Bressane, escritor, editor e jornalista paulista; Joca Reiners Terrón, escritor mato-grossense; e Xico Sá, jornalista cearense, além de editores, tradutores e professores universitários que assinaram a "Karta-manifesto" e que, em maior ou menor medida, possuem relação com o movimento. Do lado paraguaio, as redes do portunhol selvagem incluem Jorge Canese, Cristino Bogado, Edgar Pou, Susy Delgado, Miguelángel Meza, entre outros artistas e intelectuais. Porém, essas redes se ampliam enquanto comunidade de existência e de resistência aos processos de globalização e neocolonização, permitindo incluir escritores fronteiriços como Damián Cabrera e Fabián Severo, ${ }^{9}$ mesmo sem conexão direta com o "portunhol selvagem", esse "não movimento" literário, nas palavras de Diegues.

Como mencionado a princípio, estes escritores compartilham aspectos relacionados à experiência do espaço de fronteira, ao portunhol (e as outras línguas da fronteira, em Damián Cabrera) como expressão literária e à edição independente de suas obras nas duas primeiras décadas do século XXI. Fabián Severo ${ }^{10}$ é natural de Artigas, cidade localizada ao Norte do Uruguai, fronteira com a brasileira Quaraí - ligadas pela Ponte Internacional da Concórdia sobre o Rio Quaraí -, e aprendeu o portunhol em família. Douglas Diegues ${ }^{11}$ é carioca, filho de pai brasileiro e mãe paraguaia, plurilíngue de berço, cresceu em Ponta Porã, cidade sul matogrossense que faz fronteira seca com Pedro Juan Caballero. ${ }^{12}$ Damián Cabrera ${ }^{13}$ nasceu em

\footnotetext{
${ }^{9}$ Esses autores, por sua vez, constroem suas ações locais, como gestão cultural, para Damián Cabrera, as oficinas literárias, e a "edição e compilação, junto a Olga Bertinat, da Revista/Espacio de expresión cultural El Tereré, entre 2006 y 2012" (Cota, 2017, p. 3). Vale considerar também as performances de Fabián Severo com o músico uruguaio Ernesto Díaz, que compôs canções em portunhol entre os anos de 2010 e 2014, com quem participou no documentário A linha imaginária, sobre a fronteira entre o Uruguai e o Brasil, dos diretores Cíntia Langie e Rafael Andreazza.

${ }^{10}$ Seu primeiro livro foi Noite nu norte, escrito em 2008 e publicado em 2010, pela Ediciones del Rincón. Em 2013, lançou Viento de nadie e, em 2014, NósOtros. Em 2015, publicou seu primeiro trabalho em prosa: Viralata. Recentemente publicou um romance intitulado Sepultura (2020).

${ }^{11}$ Dá gusto andar desnudo por estas selvas: sonetos salvajes (2003), livro de estreia, é considerado o primeiro poemário em portunhol no âmbito hispano-americano, seguido de Uma flor na solapa da miséria (2005), El astronauta paraguayo (2007) e Rocío: sem trampas entre Pindovys y Cataratas del Yguazú (2007), La camaleoa e Berlin Paraguajénsis (2008), quando lançou Ficou gemendo pero ficou sonhando e otros sonetos, sonetos de Cruz e Sousa transdelirados ao portunhol selvagem, e depois Triple frontera dreams, versão cartonera (2012) e Interzona, de Buenos Aires, em edição aumentada (2017), e Tudo lo que você non sabe es mucho más que todo lo que você sabe (2015). Em 2019 publicou pela Era uma vez en la Frontera Selvagem (Edições Barbatana), livro infantojuvenil de contos maravilhosos em portunhol selvagem.

12 "Non se trata dum portunhol encenado desde um gabinete, pero sim ouvido primeiramente en las calles de la frontera de Punta Porã (Brasil) y Pedro Juan Caballero (Paraguay), y em ñande roga mi (nossa pequena casa), onde el portunhol era la lengua mais falada por mio abuelo, la xe sy (mi madre), la empregada, los parientes que venían a comer alli los domingos kuê. La primeira lengua en la kual me he expressado quando aprendi a falar non fue el portugues nim el español nim lo guarani, mas sim el portunhol de indole selvática. Por que selvagem? Porque que brota de las selvas de mio corazon y de los corazones de los habitantes de las selvas desconocidas de la frontera del Brasil com el Paraguay" (Gasparini et al., 2012, p. 159-160).
} 
Assunção, mas imigrou ainda criança para a região do Alto Paraná, cuja capital é Ciudad del Este, ligada a Foz do Iguaçu pela Ponte Internacional da Amizade sobre o Rio Paraná. Falante hispano-guarani, seu contato com o português e o portunhol se efetiva pelas experiências com os brasiguaios residentes na região, isso marca o distanciamento que permite uma visada crítica sobre as relações sociais na fronteira, do lado paraguaio. Publicou Xirú em 2010 em Mingua Guazú por "xirudamian.blogspot.com" e por Ediciones de la Ura em 2012. Também divulgou um fragmento por Felicita Cartonera Nembyense. Um dos personagens resgata suas experiências da infância (Cabrera, 2010, p. 68), a partir das relações subjetivas, idealizadas e conflituosas com o outro, em uma narrativa marcada pelo uso de múltiplas línguas - o espanhol, o português, o guarani e algumas evidências do portunhol - caracterizando os personagens e suas relações. Evidencia-se um processo de estratificação linguística ao longo da narrativa fragmentada, com inserções poéticas, que insinua um ritmo temporal não linear relacionado aos diversos momentos da vida do narrador-protagonista. Eminentemente usado pelas crianças nos diálogos de suas aventuras pelo espaço aberto ou em família, o guarani é mais frequente no começo da narrativa, mas sua presença no texto escasseia diante da predominância do castelhano, língua das relações sociais, da comunicação do narrador onisciente (que, por vezes, usa a segunda pessoa para pontuar as atitudes e sentimentos dos personagens), mas também língua das elucubrações íntimas do adulto, pelas quais, afirma, "me voy yendo conmigo mismo de mí".

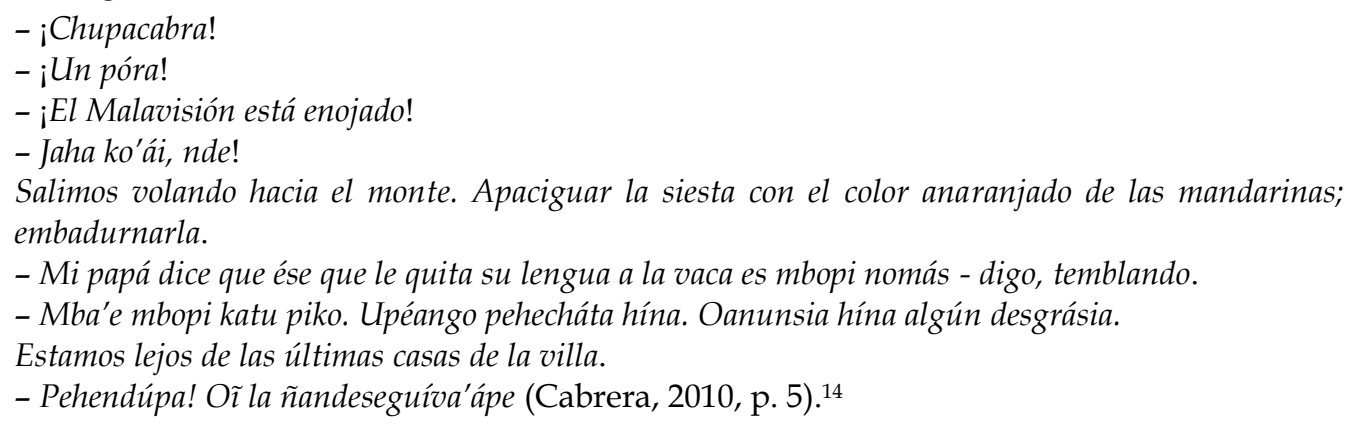

Não existe um lugar nomeado, as referências incidem sobre a paisagem e a relação dos garotos, Miguel, Nelson, Gabriel, César e outros, com a cidade, ruas, rios, campos e o entorno, depois terraplanado e cercado pelo colono brasileiro, seu Washington Cavalcante, que menospreza o paraguaio, chamando depreciativamente de "xirú" (Cabrera, 2010, p. 48). ${ }^{15}$ O conflito pela terra é determinante para essas relações, como consequência da demarcação de suas posses pelo brasiguaio e da destruição da natureza; assim, a invasão organizada pelos semterra acaba exteriorizando a tensão subjacente na narrativa. $\mathrm{O}$ uso do português também marca

\footnotetext{
${ }^{13}$ Xiru (2012) é a segunda obra publicada pelo autor paraguaio, agraciada com o Prêmio Roque Gaona. Antes publicou Sh...horas de contar (2006). Xe (2019) é seu terceiro livro. Participou das antologias Los chongos de Roa Bastos, Nueva narrativa paraguaya. Antología de cuentos, Asunción (te) mata, Punta Karaja. Cuentos de fútbol, Azar e Ya estamos caminando por esta tierra reluzente perfumada. Além disso, tem algumas publicações em revistas, como Revista Luvina, 2016 e Words Without Borders, 2020. Outros textos publicados são de não ficção .

${ }^{14}$ Em castelhano: “- ¡Chupacabra!

- ¿Un fantasma!

- ¡El Malavisión está enojado!

- ¡Vámonos de aquí!

Salimos volando hacia el monte. A apaciguar la siesta con el color anaranjado de las mandarinas, a embadurnarla.

- Mi papá dice que ese que le quita su lengua a la vaca es un murciélago nomás - digo, temblando.

- Pero qué va a ser murciélago. Es ova a ser así: es el anuncio de alguna desgracia.

Estamos lejos de las últimas casas de la villa.

- ¿Escuchan?! Aquí hay algo que nos está siguiendo".

15 "Xirú" vem de chei'ru e significa amigo em guarani, mas dito em português numa situação de dominação, ganha um tom depreciativo, observa Cota (2017, p. 3), como modo de marginalização do outro: “O xiru é preguiçoso, é só olhar pro seu Martinez. Ele acorda às cinco da manhã, toma seu chimarrão, vai pra chácara um pouquinho, volta e toma tererê embaixo da árvore; ele fica aí umas duas horas com o olhar perdido que nem esses monges, ou sei lá que diacho. Não quer trabalhar. Pra que quer terra?" (Cabrera, 2010, p. 50, tradução nossa).
} 
a autoridade do homem sobre a mulher, como a brasileira María Gonçalves e seu marido Valdir, capataz do Sr. Washington. Em contrapartida, exprime a carência da personagem, a desmemória, a fragilidade, para destacar as diferentes situações sociais em que vivem também os brasiguaios, constituindo parte dessa "comunidade" (Cota, 2017, p. 6). Com o tempo, o portunhol se apresenta como língua da marginalidade e do abandono da personagem, intensificando seu estigma de louca e pervertida, motivo pelo qual acaba sendo vítima de preconceito e segregação, ao ser representada como o Judas malhado na festa de São João e ao ter a sua casa queimada (Cabrera, 2010, p. 64), reforçando a memória do acidente que queimou seu corpo quando jovem. Esse é o ápice da tensão e do desespero em Xirú.

A ingenuidade da infância se perde em meio ao tédio de um ambiente empoeirado e quente, que oferece uma vida pacata - chegando a opressiva ao longo da narrativa. A materialização da opressão pelas ações colonizadoras dos proprietários de terras desfigura a paisagem idealizada da infância; a aventura e a ilusão dão lugar à solidão e à angústia, à desintegração do sentido de coletividade, equivalente a uma tomada de consciência de si.

Daba la impresión de que el mismo barrio era muchos, con límites imprecisos. Así lo sentí: Un vecino podía estar en la casa de junto, o a diez cuadras de distancia; quién sabe. Entonces, los barrios también podrían distinguirse unos de otros por la imponencia o humildad de las fachadas, por la lengua hablada por sus habitantes, por la forma de fumar un cigarrillo o el empleo del tiempo libre. Definitivamente, por aquí las cosas eran distintas. No era la uniformidad de mi barrio, la pulcritud. Ahí era la calle bifurcada que ofrecía la posibilidad de escoger el mal camino (Cabrera, 2010, p. 36).

A exclusão social se evidencia na condição do bairro e no tratamento dado ao outro, como no caso de Maria. Junto à tensão criada pelo fogo algoz que destrói sua casa, evidencia-se o conflito social pela posse da terra, que arde ao final como sintoma da dor comunitária, da existência compartilhada em uma sociedade que exclui o outro em seu próprio território. Como afirma Cabrera, em "Notas para representarse", "a presença visível de outras coletividades pode sugerir mais um mito que se autodestrói: integração multicultural e convivência harmoniosa; mas o diferente existe sobrevivendo hostilmente em seu espaço de acordo com seu potencial" (Cabrera, 2014, p. 169, tradução nossa). Contudo, essa convivência gera zonas de interferência, reconhece o autor mais adiante, promovendo movimentos de reterritorialização.

Por outro lado, Douglas Diegues delira nos sonhos da Tríplice Fronteira em uma coletânea de textos variados intitulada Triple frontera dreams, que teve sua primeira edição em 2012 pela Eloisa Cartonera de Buenos Aires, fundada pelo escritor Washington Cucurto e pelo artista plástico Javier Barilaro em 2003, considerada a primeira editora cartonera do continente latinoamericano. ${ }^{16}$ Com exceção da primeira publicação, Dá gusto andar desnudo por estas selvas, publicada em Curitiba pela Travessa dos editores em 2003 e da publicação de 2017 pela Interzona de Buenos Aires, toda a sua obra saiu em editoras cartoneras, tornando-se parte da sua prática artística transnacional, como a criação de Yiyi Jambo em 2007.

Yiyi Jambo es el primeiro sello editorial kartonero nômade, easy rider, itinerante, on the road... Dizem que Yiyi Jambo es una cartonera paraguaia... Pero era: porque agora non es mais... Non queremos representar a ningum país, ningum estado, ningum esquema burokrátiko oficialezko... A partir de agora moramos en la estrada, bamos y venimos driblando las alfândegas del pelotudismo... Estamos em Paraguay, em Ponta Porã, em Asunción, em Manaus, em Maceió, em Natal, em João Pessoa, em Cordisburgo, em Porto Alegre, em Curitiba, em Pedro Juan Almodóvar Caballero, em Sanber, nel hotelito del lago,

\footnotetext{
${ }^{16}$ Os livros da Eloísa Cartonera, assim como de todas as cartoneras surgidas desde então, são confeccionados artesanalmente utilizando como principal matéria-prima o papelão, comprado dos catadores da capital argentina como incentivo econômico. Segundo Javier Barilaro, a estética utilizada nos livros é a "estética da cumbia", pela grande profusão de cores que se aproxima do kitsch e do popular. O papelão é cortado para formar a capa, depois pintada com tinta guache, frequentemente variando as cores; o miolo do livro é impresso em offset ou xerox e grampeado à capa. Como parte do projeto inaugurado por Eloísa Cartonera, o esquema de produção dos livros é colaborativo e comunitário. Após isso, muitas editoras cartoneras foram fundadas na América Latina, com projetos políticos e propostas estéticas distintas, mas com processo de editoração semelhante. A primeira editora cartonera do Brasil foi Dulcinéia Catadora, de São Paulo, em 2007, fundada pela tradutora e artista plástica Lúcia Rosa, que define seu trabalho como uma prática artística colaborativa ligada ao ativismo.
} 
por supuesto... Agora Yiyi Jambo es um sello cartonero de ninguma parte... Nim del Brasil nim del Paraguay nim nacione alguma (Diegues, 2009, s.p., tradução nossa).

Triple frontera dreams reúne textos variados - na primeira edição, "La xe sy" (em portunhol selvagem e em português selvagem), "Amantes perfectos" e "El beneno de la beleza y la lokura de las yiyis" - que se avolumam significativamente na publicação da Interzona Editora. Considerando a versão inaugural da obra, percebe-se que os textos tratam da relação entre as pessoas, marcada pela multiplicidade de tipos humanos e pelo interesse sexual. O espaço é composto pela mobilidade peculiar das fronteiras, de um aeroporto em Chicago ou do ambiente urbano de Foz e "City del Este", onde circula o narrador-protagonista. Configura circunscrições não relacionais ou de relações transitórias, como são os encontros do narrador com as yiyis de passagem, "mujeres, garotas, meninas, llenas de encantos selvagens y abundante amor para dar" (Diegues, 2017, p. 30), que podem se situar em qualquer lugar no mundo.

Nel mezzo del deserto de Sam Paulo, Campo Grande, Curitiba ou Asunción, deserto lleno de perros sorridentes y niñas bonitas, mio korpo viciado em tus lábios carnudos, tu pele macia, tu koncha cremosa, tu bunda afruguaranga, tu xocolate salvaje, tu miel de verdade, mio korpo viciado em tuo veneno, procura bocê, mas non acha nada (Diegues, 2012, p. 21).

O portunhol selvagem cria o ritmo alucinado dessas narrativas, marcadas pela repetição em espiral de frases e termos, pela ortografia variada e a mistura de palavras de línguas diversas, sem desenvolver uma linha coerente para a ação, o que resulta em uma sensação de vertigem de imagens justapostas. Ainda que a edição de 2017 inclua mitos e lendas da cultura popular de diferentes origens, que compõem a paisagem da interface Brasil-Paraguai, expressos na perspectiva do portunhol selvagem - "Mio amigo el Pombêro", "Kurupi", "El xamán milagroso", "Las ranas y los sapos", "Las Moñai", "Yaguaretê-Abá", "Indio Ramírez", "Pájaro Benítez", ou mesmo o Karnicero de Milwaukee de "Amantes perfectos" (Diegues, 2017, p. 95) -, grande parte dos textos percorre as relações intelectuais, amorosas e de amizade do protagonista no espaço fronteiriço. Existem referências a escritores de várias nacionalidades, que traçam as redes literárias do autor nessa obra; entre inúmeros nomes, por exemplo, aparecem os de Jamil Snege, Dani Umpi, Fabián Casas ou Leopoldo María Panero, a quem dedica um texto poético-prosaico para qualificar um mundo desajustado, onde o único sentido válido está no encontro, na amizade e no amor (Diegues, 2017, p. 53). Contudo, o texto de maior interesse para esta análise, que tem o mesmo título da obra Triple frontera dreams, foi incluído na edição de Interzona, mas não na primeira edição. Descreve o ambiente da tríplice fronteira, as cidades interconectadas pela Ponte da Amizade, como um espaço que iguala a pluralidade de seres em função do seu movimento e anonimato, o que, por outro lado, encoberta a transgressão e a miséria. Apesar disso, constitui-se pela efervescência multicultural que expõe a "fauna triple frontera" (Diegues, 2017, p. 18), criando uma paisagem urbana peculiar, colorida, musical e olfativa, através da qual transita $o$ protagonista em uma perspectiva não identificada com a maioria, "las manadas generalmente se encontram hipnotizada por los hits de buesta del momento" (Diegues, 2017, p. 20). O protagonista avança pela noite "paraguayensis", entre ruas, bares e histórias, para comprovar que "la realidade delira diariamente em la triple frontera" (Diegues, 2017, p. 27). O "glossariocito selvatiko" inserido ao final do texto, uma prática comum em várias obras do autor, afiança a multiplicidade de línguas que atravessam o espaço narrado em Triple frontera dreams, como o guarani-paraguaio, o nivaklê, o árabe e o italiano, formando um mosaico de imagens pelas palavras, que intensifica os deslocamentos do portunhol selvagem em clave antropofágica.

Por último, como a maioria das obras de Fabián Severo (somente a primeira foi uma edição de autor), Viralata foi publicado pela Rumbo Editorial, apresentada em sua página do Facebook como uma editora independente, que busca divulgar as "novas vozes da literatura uruguaia". É um relato em primeira pessoa que conta, a partir da velhice do protagonista, a angústia de um menino em busca de sua linhagem familiar. Órfão de mãe, sem conhecer seu pai, ${ }^{17}$ ele procura

\footnotetext{
17 "En Artigas, nuestras madre sempre se llaman Soledad y todos nuestros padre se perderon nus pasto buscando dónde se prenden los arco-íris" (Severo, 2015, p. 46).
} 
informações entre os vizinhos na cidade de Artigas, enfatizando a força da oralidade para a construção da memória. Contudo, as informações que consegue levantar são imprecisas, isso projeta no texto um sentido de vacuidade que não pode ser preenchido.

La historia de una persona se parece a una nube de malentendidos. El pasado que los vecino cuentan, asvés, tiene poco que ver con los recuerdo que uno tiene. La vida es un rompe cabeza onde las parte nunca encajan y uno tiene que invertarse las propia pieza siempre que tenga que contarse. [...] Yo tenía impezado el largo camino de plantarme y desplantarme, de morir y nacer muchas vez. Las semilla del no saber ya tenían dado los primer brote adentro de mi cabeza, y mis pie istaban aprendendo a preguntar (Severo, 2015, p. 15-16).

Essa consciência é alcançada logo no começo da narrativa e vai se intensificando pela repetição, cada vez mais dramática, da imagem da árvore desconhecida e da semente abandonada, mediante o choque entre a expectativa da origem e a frustação pela sua inexistência: "soy el sin nombre. Hijo del gastado borde de un mapa. Hijo du silencio y del olvido" (Severo, 2015, p. 37). Mesmo se chamando Fabi, o protagonista se apresenta como uma singularidade plural, que se reconhece como "ninguém" somente a partir da analogia com os outros "filhos do esquecimento", numa relação dentro-fora que se constitui a partir do relato. Aos retalhos do passado, o narrador contrapõe um tecido de palavras para alinhavar o presente e criar a narrativa em seus cadernos. Para ele, as palavras não curam a morte, mas revivem os afetos, desde que encontrem alguém que as leia, como percebe ao final da sua existência. Assim, a linguagem passa a ser o espaço do compartilhamento e da rede afetiva do narrador, as interferências fronteiriças são o ruído do caminho percorrido: "tal vez, los oído acostumbrado con el ruido de otros lugar, no intendan mi lengua de tierra, no sepan por qué mi voz sale molida. Es la tristeza que aplasta palavras, abatuma sonidos" (Severo, 2015, p. 92). A tristeza é o tom de sua narrativa, o registro de quem permaneceu preso ao passado e ao espaço da fronteira, escrevendo para não esquecer. Nesse caso, o espaço da fronteira, diferente da tensão social pela posse da terra, em Damián Cabrera, ou da efervescência cultural, de Douglas Diegues, é assinalado pela angústia e pela negatividade da existência.

Na fronteira, o tempo é parado, o relógio da estação não envelhece e marca a hora que não é (Severo, 2015, p. 127), porque faz 20 anos que são nove horas (Severo, 2015, p. 20). O sentido de estagnação da vida aumenta com a repetição de imagens como essa, indicando a ausência de desenvolvimento da região, insinuando que a fronteira está fora da história. Na perspectiva do narrador, equivale a um espaço de miséria e de complexidades: "las frontera es onde dos país se atraviesan. Es un destino muy disparejo para intrar en una palabra. Por isso, cualquieruno de nosotro, istá obligado, todo u tempo, a assumar la mirada, a remendar los pie, a interpretar las dudas. La frontera no tiene fin" (Severo, 2015, p. 171). O "nós" a que se refere, para dizer daqueles que compartilham a experiência da fronteira, diferentemente do seu tempo e apesar das limitações sociais que encerram seus seres, não é estagnado, mas "heterogêneo, deslocado e mutante", como afirmou Achúgar, possível somente a partir da relação, do "ser-em-comum", como entendeu Nancy, por isso faz parte do mundo enquanto pluralidade - "nós também semo el mundo" (Severo, 2015, p. 129, 132). O mundo é a infinitude de finitudes singulares, que nascem e morrem várias vezes porque não se reduzem a uma essência.

Todos. Mi madre, la Mama, mi padrino, la Tania y yo, unidos numa especie de soledad imparejada, como una cadena invisible que ata nuestros pie en las piedra de la frontera. Nacimo y morremo varias vez, desincontrados, misturando las versión, martillando los recuerdo, cosiendo los ojo para intentar descubrir un rayo de sol en las cueva de nuestras vida (Severo, 2015, p. 65).

O bairro, a casa, a família estão desprovidos de estabilidade e unidade, por isso a solidão que os personagens fronteiriços compartilham durante sua existência, e não a comunhão, caracteriza o seu ser-em-comum, a sua "comunidade". O protagonista não tem origem, a terra não lhe pertence, só tem certeza da morte, porém a memória da mãe e da infância define uma relação com a vida. Ao longo da narrativa, em um tom melancólico, o narrador se pergunta sobre a nulidade da existência na fronteira e sobre a miséria humana. Na velhice, enfim, percebe que as lembranças são sua árvore: "vivi equivocado toda la vida [...] me rascando los recuerdo para ser al fin un viejo apagado que aprendió tarde que uno sólo puede ser feliz con otro" (Severo, 2015, p. 195, 
196). Desse modo, a narrativa se torna sua vida, já que sua memória foi inventada como recurso para sobreviver à morte que o ameaçava pela ausência de origem.

\section{Existências expostas em palavras}

Se fosse possível resumir em subtítulos as diversas expressões em portunhol e outras línguas em tensão das comunidades de existência nas fronteiras entre o Brasil, o Paraguai e o Uruguai, nos autores e obras elencados nesta reflexão, poderiam ser "Douglas Diegues e a conexão paraguayensis", "Damián Cabrera e a policromia fronteiriça", "Fabián Severo e o afeto da soleira", como deslocamentos narrativos dentro-fora da expressão literária contemporânea. Articulados e desarticulados, sua produção em editoras independentes, em blogs e sites da internet, alimenta as redes literárias na América Latina enquanto singularidade plural, não identidade imanente ou absoluta. Os autores estudados compartilham a rede inoperada das literaturas de fronteiras, porque não querem fazer "obra", como canonizar ou gramaticalizar as escritas em portunhol. Sua impossibilidade, diante das determinações da literatura padronizada, viabiliza um caminho capaz de ser percorrido pela expressão artística, compartilhado na exposição da singularidade, por meio de línguas que atuam num espaço transitivo e praticado, um espaço antropológico e existencial que não se fecha, porque constantemente se des(re)territorializa na relação. Por esse motivo, o portunhol se caracteriza pela agramaticalidade, pelo jogo de palavras que fala de um lugar deslocado. As fronteiras se caracterizam pela relação, seja de libertação ou de dominação, marcadas pela multiplicidade, heterogeneidade e hibridismo que se manifestam como tensão da existência no espaço natural e social em Damián Cabrera, como melancolia de um sentido ausente que se converte em palavras e memórias inventadas em Fabián Severo, ou como gozo do presente pelo delírio da vida e da partilha em Douglas Diegues. Uma comunidade de existência que se articula nas ações desses escritores, para além das limitações das literaturas nacionais e da historiografia literária, formando-se no contato e na relação das redes literárias nas primeiras décadas do século XXI.

\section{Referências}

ACHÚGAR, Hugo (2006). Planetas sem boca. Tradução de Lisley Nascimento. Belo Horizonte: Editora UFMG.

AGAMBEN, Giorgio (2013). A comunidade que vem. Tradução de Cláudio Oliveira. Belo Horizonte: Autêntica.

ALÓS, Anselmo Peres (2012). Portuñol selvagem: da "língua de contato" à poética da fronteira. Revista de Letras da UFF, Niterói, n. 45, p. 289-304.

BANCESCU, María Eugenia (2013). Fronteras del centro/fronteras de la periferia: sobre el portunhol selvagem de Douglas Diegues. Sures, Foz do Iguaçu, n. 1, 1-13.

BERND, Zilá (2003). Americanidade e transferências culturais. Porto Alegre: Movimento.

CABRERA, Damián (2010). Xirú. Blog. Disponível em: xirudamian.blogspot.com. Acesso em: 20 jan. 2020.

CABRERA, Damián (2014). Notas para representarse. Decires en frontera. In: PEREIRA, Diana Araújo. Cartografia imaginária da tríplice fronteira. São Paulo: Dobra Editorial. p. 167-180.

CATONIO, Angela Cristina Dias do Rego (2018). Palabras tortas: o portunhol literário de Fabián Severo e Douglas Diegues. Tese (Doutorado) - Universidade Estadual Paulista, Assis.

COTA, Débora (2017). Xirú: barro, comunidade e identidade em uma narrativa fronteiriça. RELAcult Revista Latino-Americana de Estudos em Cultura e Sociedade, Foz do Iguaçu, v. 3, ed. especial, p. 1-8.

DELEUZE, Gilles; GUATTARI, Félix (1995). Mil platôs. Capitalismo e esquizofrenia. v. 1. Tradução de Aurélio Guerra Neto e Celia Pinto Costa. São Paulo: Editora 34.

DIEGUES, Douglas et al. (2008). Karta-Manifesto-del-Amor-Amor-en-Portunhol-Selvagem, O Globo, 17 ago. Disponível em: https://oglobo.globo.com/cultura/confira-manifesto-em-defesa-do-portunholselvagem-3607777. Acesso em: 23 jan. 2020. 
DIEGUES, Douglas (2009). [Entrevista a] Julio Daio Borges. Digestivo Cultural, São Paulo, $1^{\circ}$ jan. On-line. Disponível em: http://bit.ly/3ajcNJk. Acesso em: 20 jan. 2020.

DIEGUES, Douglas (2012). Triple frontera dreams. Buenos Aires: Eloísa Cartonera.

DIEGUES, Douglas (2017). Triple frontera dreams. Buenos Aires: Interzona.

GASPARINI, Pablo et al. (2012). Corregirlo sería matarlo. [Entrevista a] Douglas Diegues, poeta em "portunhol selvagem miri michi". Abehache, ano 2, n. 2, p. 159-166.

LUDMER, Josefina (2010). Aquí América Latina. Una especulación. Buenos Aires: Eterna Cadencia.

NANCY, Jean-Luc (2016). A comunidade inoperada. Tradução de Soraya Guimarães Hoepfner. Rio de Janeiro: 7Letras.

OLIVEIRA JÚNIOR, Josué Ferreira (2018). Literatura, fronteiras e margens: poéticas fronteiriças na fronteira Brasil-Paraguai. Linguas e Letras, Cascavel, v. 19, n. 42, p. 23-39.

PERLONGHER, Néstor (2000). El portuñol en la poesía. Tsé tsé, Buenos Aires, n. 7/8, p. 254-259.

PORTILLO, Diego Emanuel Damasceno (2018). Uma poética desterritorializada em Mar Paraguayo. 2017. Dissertação (Mestrado) - Universidade Federal do Paraná, Curitiba.

RANCIÈRE, Jacques (2005). A partilha do sensível: estética e política. Tradução de Mônica Costa Netto. São Paulo: Editora 34.

SEVERO, Fabián (2012). Poesía de frontera. Qué palabra es de dónde en la geografía de la Poesía. Ponencia presentada en el Encuentro de Jóvenes Escritores de América Latina y el Caribe en la Feria Internacional del Libro. La Habana: 14 fev. Disponível em: http://fabiansevero.blogspot.com/2012/02/poesia-defrontera-que-palabra-es-de.html. Acesso em: 3 fev. 2020.

SEVERO, Fabián (2015). Viralata. Montevideo: Rumbo Editorial.

TRIGO, Abril (1997). De la transculturación (a/en) lo transnacional. In: MORAÑA, Mabel (Ed.). Ángel Rama y los estudios latinoamericanos. Pittsburgh: IILI. p. 147-172. 